\title{
Selection of egg attachment sites by the Indian Golden Gecko Calodactylodes aureus (Beddome, 1870) (Reptilia: Gekkonidae) in Andhra Pradesh, India
}

\author{
R. Sreekar ${ }^{1}$, C. Srinivasulu ${ }^{2}$, M. Seetharamaraju ${ }^{3} \&$ C. Aditya Srinivasulu ${ }^{4}$ \\ 1,4 Biodiversity Research and Conservation Society, \# G4, MRK Towers, Swarnadhamanagar, Old Bowenpally, Secunderabad, \\ Andhra Pradesh 500011, India \\ ${ }^{2,3}$ Wildlife Biology Section, Department of Zoology, University College of Science, Osmania University, Hyderabad, Andhra Pradesh \\ 500007, India \\ Email: ${ }^{1}$ sreekar1988@gmail.com, ${ }^{2}$ hyd2masawa@gmail.com (corresponding author)
}

Date of publication (online): 26 October 2010 Date of publication (print): 26 October 2010 ISSN 0974-7907 (online) | 0974-7893 (print)

Editor: Aaron Bauer

Manuscript details:

Ms \# 02393

Received 22 January 2010

Final received 19 May 2010

Finally accepted 23 August 2010

Citation: Sreekar, R., C. Srinivasulu, M. Seetharamaraju \& C.A. Srinivasulu (2010) Selection of egg attachment sites by the Indian Golden Gecko Calodactylodes aureus (Beddome, 1870) (Reptilia: Gekkonidae) in Andhra Pradesh, India. Journal of Threatened Taxa 2(11): 1268-1272.

Copyright: (C) R. Sreekar, C. Srinivasulu, M. Seetharamaraju \& C. Aditya Srinivasulu 2010 Creative Commons Attribution 3.0 Unported License. JoTT allows unrestricted use of this article in any medium for non-profit purposes, reproduction and distribution by providing adequate credit to the authors and the source of publication.

Author Contributions: All the authors have equally participated in field surveys; RS kept detailed notes on numbers of eggs at all sites and conducted analysis; RS and CS planned the paper and others contributed equally in writing the paper.

Author Details and Acknowledgements: see end of this article.
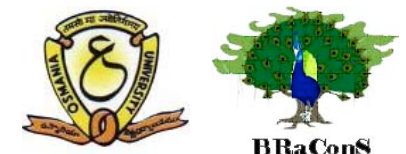

BRaCons

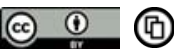

OPEN ACCESS | FREE DOWNLOAD
Abstract: Some geckos lay eggs at communal egg deposition sites with as many as 300 eggs per site. Selection of egg deposition sites is important to avoid egg damage and predation. We investigated survival rates of communal egg clutches of the Indian Golden Gecko Calodactylodes aureus (Reptilia: Gekkonidae). Our results show that communal clutches have a higher survival rate in sites with water bodies and without anthropogenic activities, in comparison to sites having the opposite combination. These findings are discussed in the context of the status of this gecko.

Keywords: Calodactylodes aureus, disturbance, egg number, egg damage, habitat, Indian Golden Gecko, site selection.

\section{INTRODUCTION}

The Indian Golden Gecko Calodactylodes aureus (Beddome, 1870) was rediscovered in 1986 after more than 100 years (Daniel et al. 1986; Russell \& Bauer 1989). The genus Calodactylodes (Beddome, 1870) is restricted to tropical South Asia and is represented by two species: the Indian Golden Gecko Calodactylodes aureus (Beddome, 1870) and the Sri Lankan Golden Gecko Calodactylodes illingworthorum (Deraniyagala, 1953). The Indian Golden Gecko is distributed along the coastal hills of Andhra Pradesh, southern Chhattisgarh, southern Orissa and northern Tamil Nadu regions of India (Daniel et al. 1986; Molur \& Walker 1998; Bauer \& Das 2001; Dutta et al. 2005; Javed et al. 2007) and had long been considered rare and poorly known (Russell \& Bauer 1989; Molur \& Walker 1998; Mirza et al. 2010). This gecko prefers rocky areas with deep stream valleys and has been observed at elevations between 50 and $1000 \mathrm{~m}$. The gecko has been reported to lay eggs in communal egg deposition sites (Bauer \& Das 2001; Javed et al. 2007) on rocky surfaces, mostly on vertical rocks, in both natural and human-inhabited areas. The present study was designed to throw light on the selection of egg deposition sites and survival rates of the Indian Golden Gecko.

\section{MATERIALS AND METHODS}

Study Area: The study was conducted in three different localities of Andhra Pradesh, India (Image 1): Perantalapally, Khammam District ( $17^{\circ} 27^{\prime} \mathrm{N}$ \& 81046'E, elevation 53m); Ananthagiri Hills, Visakhapatnam District (18014'N \& 82 $52^{\circ}$ 'E, elevation $1000 \mathrm{~m}$ ) and Maredumilli, East Godavari District ( $17^{\circ} 56^{\prime} \mathrm{N}$ \& $82^{\circ} 23^{\prime} \mathrm{E}$, elevation $\left.900 \mathrm{~m}\right)$. These areas mainly receive rainfall from the southwest monsoon; average rainfall is approximately $900-1700 \mathrm{~mm}$, mostly between June and October (Javed et al. 2007; Pattanaik et al. 2009). The Ananthagiri Hills support a vegetation of mixed deciduous forests with orchids 


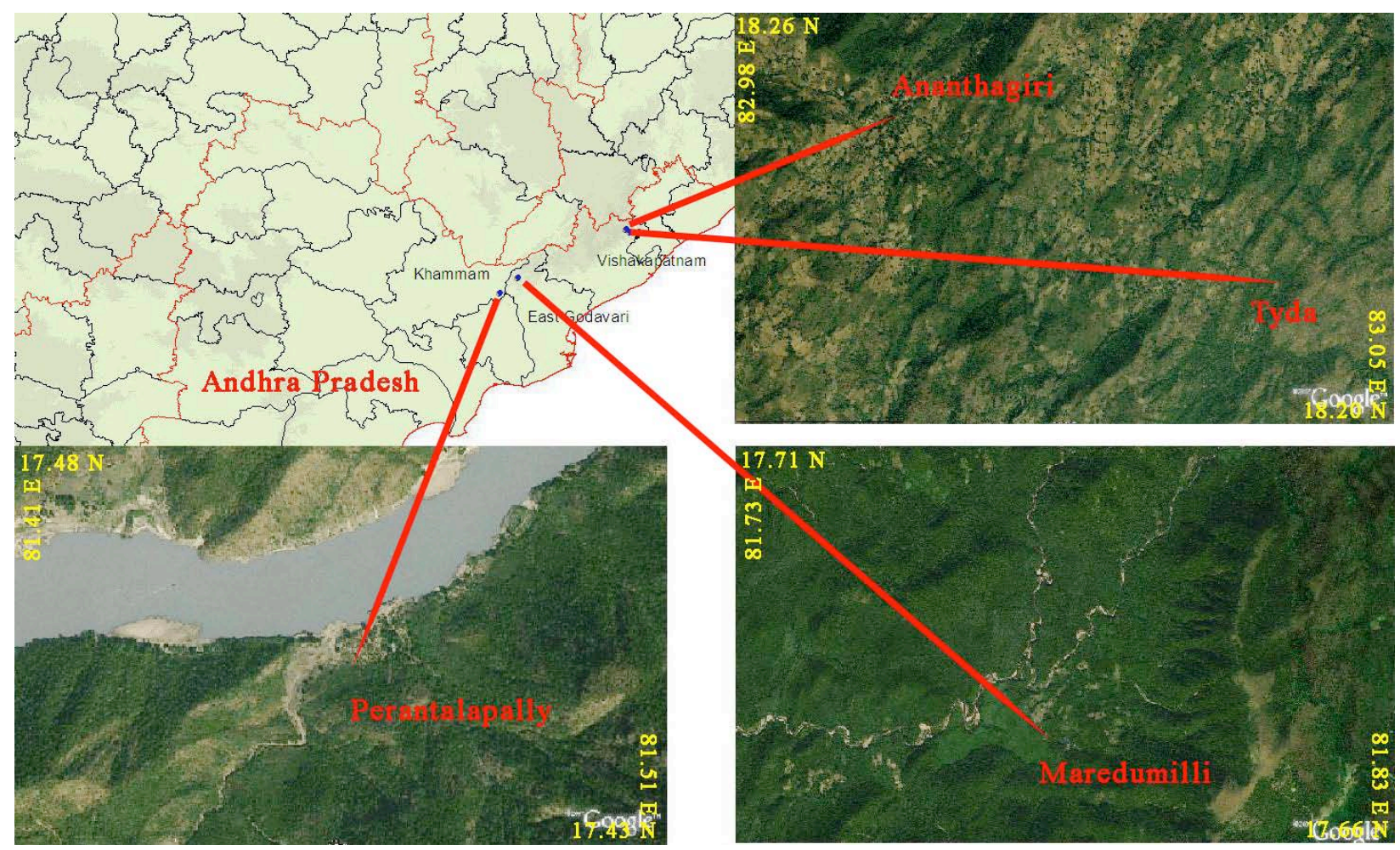

Image 1. Map indicating the locations of the study sites in Andhra Pradesh, India

and ferns as undergrowth. The forests are mainly secondary forests due to the practice of shifting cultivation and most of the slopes in human occupied areas are dominated by coffee plantations. Cultivation is mostly practiced close to seasonal streams. Perantalapally and Maredumilli are characterized by typical southern dry deciduous forests with patches of moist deciduous forest intermingled with scrub. The moist deciduous forests are commoner in valleys and bordering the streams. The study was conducted in wet and dry areas, undisturbed and disturbed habitats.

The study was conducted between January 2008 and August 2009 ( $n=53$ days). Extensive studies were conducted in the months of July and August ( $n=37$ days), when the geckos are active, laying eggs. Strip transects of $1000 \mathrm{~m}$ length were laid randomly in and around suitable rocky habitat and human occupied areas and visually searched for active and hidden geckos. Gravid females are usually sighted around the egg clusters. The following data were noted: number of eggs, number of geckos around the cluster, distance from the ground, habitat type, microhabitat type, and distance from water. Repetitive surveys were made to the localities with eggs to note the damage that accrued over time. Damage in human habitations was noted visually and assessed based on obtained verbal reports from local people. Activity of these geckos was observed both at day and night with the help of flash lamps. The reptiles that are sympatric with these geckos were examined and identified using keys provided in Smith $(1935,1943)$ and descriptions in Whitaker \& Captain (2004). No samples were collected during the study.

Analysis: To evaluate the differences between sites and other parameters studied, statistical analysis and tests were conducted in the programming and statistical language R 2.9.0 (R Development Core Team 2009). We used two statistical approaches to identify specific factors correlated in determining the best egg site type: Welch's two sample t-test and linear modeling.

Welch's two sample t-test: We classified the egg sites into two areas: wet area and dry area. Wet area included habitats with streams, ponds, wells and public bathrooms (Image 2), which had lower temperatures and high humidity. Dry area included boulders away from water bodies and store rooms, which had higher temperatures and low humidity. The number of eggs at each locality was noted. We used this test to check the difference between numbers of eggs at each site in different areas.

Linear modeling: We classified the eggs sites into two categories: undisturbed and disturbed sites. Undisturbed sites represent natural habitats away from human habitation (> 1 km) (Image 3 ) and disturbed sites represent altered habitats with anthropogenic influences (Image 4). The number of eggs in a cluster at the site and number of eggs damaged by anthropogenic or other animal disturbances were noted by making regular visits to the egg sites. The damage is estimated by recognizing the missing eggs that were not yet developed by photo 


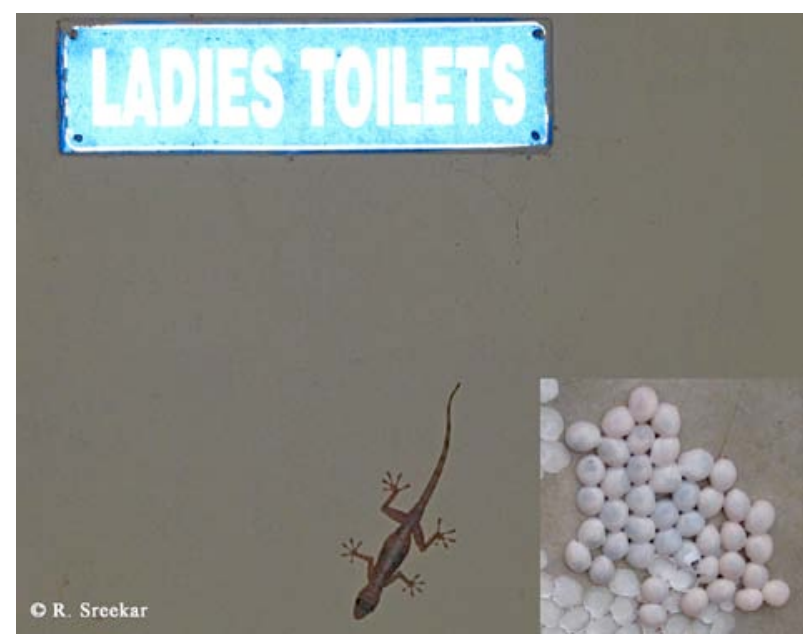

Image 2. A gravid female at an egg depositing site with anthropogenic disturbance at Ananthagiri, Visakhapatnam District, Andhra Pradesh (inset showing an egg clutch from the site)

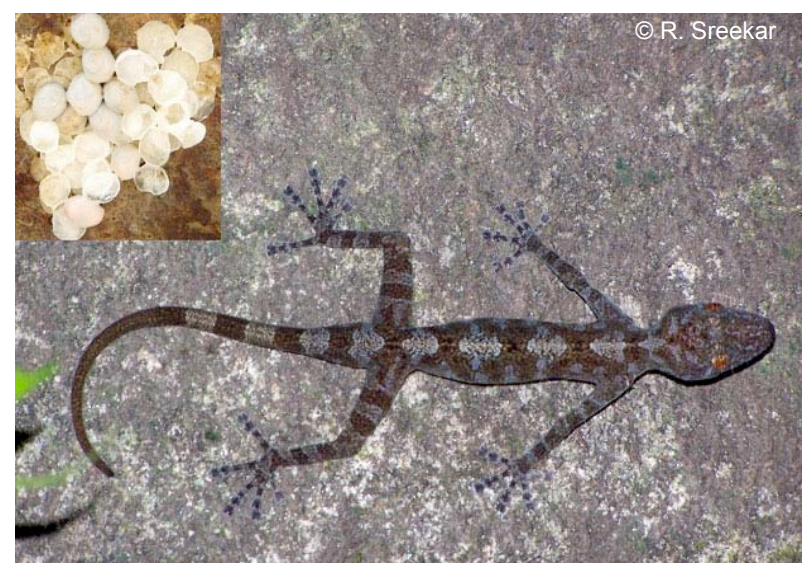

Image 3. An Indian Golden Gecko in its natural habitat at Perantalapally, Khammam District, Andhra Pradesh (inset showing an egg clutch from the site)

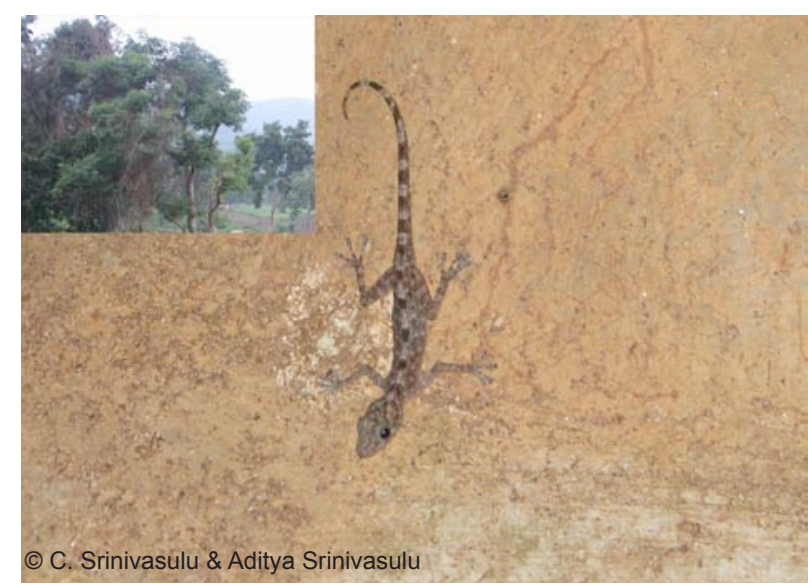

Image 4. An Indian Golden Gecko in its disturbed habitat at Tyda, Visakhapatnam District, Andhra Pradesh (inset showing declining habitat quality at the site) documenting the clutches on a daily basis, personal observations and by conducting questionnaire-based surveys at human habitations as the maximum damage in disturbed sites is by humans. We used linear modeling to determine the relationship between the total number of eggs in a cluster and the number of eggs damaged in the cluster. The damage rate was quantified by dividing the mean number of damaged eggs by the mean number of total eggs. We used a scatter plot to represent the data.

\section{RESULTS}

Wet and dry areas: Over a one year period, we monitored 40 egg deposition sites, of which 28 (70\% of the total egg sites) were in wet areas and 12 (30\% of the total egg sites) were in dry areas. We found a large difference in the number of eggs in the different zones (Welch's two sample t-test: $t=3.8315$; $d f=27.224 ; p=$ 0.0006828 ) with a mean value of $46.92(S D=58.24, n=$ 28 ) and $4.66(S D=2.46, n=12)$ eggs in the wet zones and dry areas respectively. Thus wet areas have greater egg densities.

Disturbed and undisturbed sites: In the 40 monitored sites, 27 (67.5\% of the total egg sites) were in undisturbed sites and 13 (32.5\% of the total egg sites) were in disturbed sites. Egg damage was observed in $54 \%$ of disturbed sites $(n=13)$ and in $41 \%$ of undisturbed sites $(n=27)$. In the sites with disturbance, causes of damage appeared to be primarily due to clearing the egg sites. The damage rate calculated was $97.2 \%$ in disturbed sites. In these sites we found that the damage rate was very high and was significantly correlated with the total number of eggs, a $p$ of $5.193 e-08$ was obtained (Fig. 1). The primary cause of damage is the cleaning of egg sites

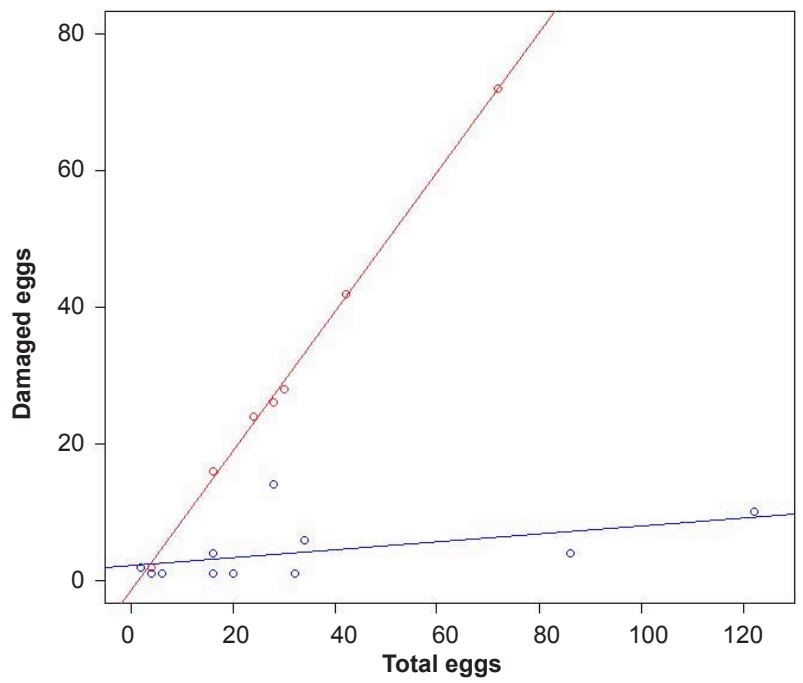

Figure 1. A scatter plot showing the amount of damage in disturbed (red) and undisturbed (blue) sites. 
by locals living at the sites who were not comfortable with sight of the egg clusters, especially in great numbers. In the undisturbed sites, the damage rate was $12.3 \%$. The causes of damage appeared to be primarily related to ant, rodent and other small mammal predation. In these sites we found that the number of eggs damaged is not correlated with the total number of eggs in the cluster ( $p$ $=0.1201)$. Despite the insignificance, the damage rate correlates the total number of eggs (Fig. 1) except for one case where a major part of the cluster fell prey to an animal overnight.

\section{DISCUSSION}

The most notable feature of this study is the contrast in the selection of oviposition sites by the Indian golden gecko. This is represented by numbers, habitat selection and particularly in their responses to human disturbances. Predation by animals was observed in wet areas. In one case, ants were observed puncturing the egg and carrying the embryo into their nest. The embryo was yellow with large eyes that covered a major part of its head. In sites with anthropogenic activity most of the eggs were encountered in public bathrooms and a good number of gravid females were also sighted around these sites.

In sites with anthropogenic disturbances, the number of damaged eggs is almost equal to the number of eggs laid. In sites without anthropogenic disturbances, the damage is highly correlated with the physical situation of the site where external factors like microhabitat type and distance from the ground are involved. The sites that have eggs attached to roofs of caves averaging more than three meters from the ground and the sites in which eggs are laid in crevices have greater success relative to the eggs that are laid at a distance less than one meter from the ground (present observation). In these sites the egg clutches are vulnerable to small mammals.

The Indian Golden Gecko forages by ambushing and we have observed them to be active both in the day as well as night. They were mostly observed preying on spiders and in some occasions mid-air acrobatic twirls were made by the gecko while jumping from one rock to another and catching prey in mid air. The long limbs of these geckos are perfectly designed for performing the above mode of foraging. In and around human habitations, they are often attracted to lights that also attract insect prey and there they chiefly prey on moths. The geckos escape into crevices when threatened, and, as ambush predators, are capable of bursts of high speed (Huey 1982; Nagy et al. 1984).

According to the local tribal community, the geckos lay eggs throughout the year. However, this phenomenon was not observed by us at any of the 40 sites monitored during the present study, where viable eggs where only present between late June to September.
Status: At Perantalapally, Khammam District, Andhra Pradesh, the Indian golden geckos were observed to be most common along streams. Such localities had the highest density among the study sites. This habitat is under great threat due to the construction of Indira Sagar Multi-purpose Project (Polavaram Dam) that will submerge the habitat (Javed et al. 2007). Other reptiles found in sympatry are Hemidactylus frenatus (Schlegel, 1836), Calotes rouxii (Duméril \& Bibron, 1837) and Bungarus caeruleus (Schneider, 1801). In the Ananthagiri Hills, Visakhapatnam District, Andhra Pradesh this species is under threat from human encroachment and conversion of streams into farm lands. The geckos and their habitat here are also threatened by proposed bauxite mining activity by the Andhra Pradesh Mineral Development Corporation Limited, which would destroy the available pristine habitat (Pattanaik et al. 2009). Other reptiles found in sympatry are Hemidactylus brookii Gray, 1845, H. frenatus (Schlegel, 1836), H. leschenaultii (Duméril \& Bibron, 1836), an unidentified Hemidactylus sp., Hemiphyllodactylus aurantiacus (Beddome, 1870), Psammophilus blanfordanus (Stoliczka, 1871), Eutropis carinata (Schneider, 1801) and Lycodon aulicus (Linnaeus, 1758). This species has been observed in human habitations at Ananthagiri (Image 2) and Tyda (Image 4). Maredumilli, East Godavari District, Andhra Pradesh is the only site that is not under threat and supports a large population of this species. Other reptiles found in sympatry are Geckoella nebulosa (Beddome, 1870), Hemidactylus frenatus (Schlegel, 1836), H. brookii Gray, 1845 and Ptyas mucosa (Linnaeus, 1758).

Trade was considered to be a major threat to this endangered gecko (Molur \& Walker 1998) but the current study shows that human interference can be a greater problem as most of the geckos habitats outside protected areas in northeastern Andhra Pradesh seem to be threatened by human disturbances. The preferred solution would be building special water tanks around human habitations for the Indian Golden Gecko to deposit their eggs. Long term management planning using combination of measures might benefit geckos and the locals.

\section{REFERENCES}

Bauer, A.M. \& I. Das (2001). A review of the gekkonid genus Calodactylodes (Reptilia: Squamata) from India and Sri Lanka. Journal of South Asian Natural History 5(1): 25-35.

Daniel, J.C., B. Bhushan \& A.G. Sekar (1986). Rediscovery of the Golden gecko Calodactylodes aureus (Beddome) in the Eastern Ghats of Andhra Pradesh. Journal of the Bombay Natural History Society 83: 15-16.

Dutta, S.K., B. Mohanty \& P.P. Mohapatra (2005). Niyamgiri unraveled. Sanctuary Asia Magazine October: 56-59.

Huey, R.B. (1982). Phylogenetic and ontogenetic determinants of sprint performance in diurnal kalahari lizards. Koedoe 25: 43-48.

Javed, S.M.M., A. Waran \& F. Tampal (2007). On the occurrence 
of Golden Gecko Calodactylodes aureus in Papikonda Hills, Eastern Ghats, India Zoo's Print Journal 22(6): 2727-2729.

Mirza, Z.A., S. Pal \& R.V. Sanap (2010). Notes on a ground gecko Geckoella cf. collegalensis Beddome, 1870 (Squamata, Sauria, Gekkonidae) from India. Russian Journal of Herpetology 17(1): 8-14.

Molur, S. \& S. Walker (eds.) (1998). Report of the Workshop "Conservation Assessment and Management Plan for Reptiles of India". Zoo Outreach Organization and Conservation Breeding Specialist Group, Coimbatore, India, 175pp.

Nagy, K.A., R.B. Huey \& A.F. Bennett (1984). Field energetics and foraging mode of Kalahari lacertid lizards. Ecology 65: 588-596.

Pattanaik, C., S.N. Prasad \& C.S. Reddy (2009). Need for conservation of biodiversity in Araku Valley, Andhra Pradesh. Current Science 96(1): 11-12.

R Development Core Team (2009). R: A Language and Environment for Statistical Computing. R Foundation for Statistical Computing, Vienna, Austria.

Russell, A.P. \& A.M. Bauer (1989). The morphology of the digits of the golden gecko, Calodactylodes aureus and its implications for the occupation of rupicolous habitats. Amphibia-Reptilia 10(1989): 125-140.

Smith, M.A. (1935). The Fauna of British India, Including Ceylon and Burma. Reptilia and Amphibia Vol. II - Sauria. Taylor and Francis, London, xiii+440pp+2 folding maps+1pl.

Smith, M.A. (1943). The Fauna of British India Ceylon and Burma Including the Whole of The Indo-Chinese Region Vol. III Serpentes. Taylor and Francis, London, 583pp+1 map.

Whitaker, R. \& A. Captain (2004). Snakes of India: The Field Guide. Draco Books, Chennai, xiv+481pp+4pl.
Author Details: MR. R. SREEKAR is an independent field researcher attached with Biodiversity Research and Conservation Society, Secunderabad. His interest lies in herpetofauna and ornithology.

Dr. C. SRinivasulu is Assistant Professor in Department of Zoology. He is the head of the research laboratory at Osmania University that focuses on biodiversity inventorying, conservation, ecology and animal taxonomy with special reference to Eastern Ghats and Godavari River basin in Andhra Pradesh.

Mr. M. SeEtharamaraju is pursuing his doctoral work on snake diversity and taxonomy in Telengana region of Andhra Pradesh at Department of Zoology, Osmania University, Hyderabad, under the supervision of Dr. C. Srinivasulu. $\mathrm{He}$ is interested in documenting and studying biodiversity in Andhra Pradesh.

Mast. C. Aditya SRInivasulu is a student researcher with Biodiversity Research and Conservation Society in Secunderabad. His interest lies in biodiversity studies and conservation education.

Acknowledgements: The authors are very much thankful to Shri Hitesh Malhotra, IFS, Principal Chief Conservator of Forest (Wildlife) and Chief Wildlife Warden, Govt. of Andhra Pradesh; Dr. R. Hampaiah, Chairman and Dr. V.B. Ramanamurthy IFS, Member Secretary, Andhra Pradesh Biodiversity Board, Govt. of Andhra Pradesh, Hyderabad for constant support and encouragement in biodiversity documentation and studies. The first author thanks Romulus Whitaker and Matt Goode for their useful comments on the rough draft and Shreyas Krishnan for his constant support and encouragement. We also thank Prof. T. Tirupathi Rao, Vice Chancellor, Osmania University and the Head, Department of Zoology, Osmania University, Hyderabad for encouragement and facilities. 